\title{
Intelligent read-out circuit for space radiation detection
}

\author{
'Umar Abdul Aziz ${ }^{1}$, Siti Fauziah Toha' ${ }^{2}$ Rabiatuladawiah Abu Hanifah ${ }^{3}$, Nurul Fadzlin Hasbullah ${ }^{4}$ \\ ${ }^{1,2,3}$ Department of Mechatronics Engineering, Faculty of Engineering, International Islamic University Malaysia, \\ Kuala Lumpur, Malaysia \\ ${ }^{4}$ Department of Electrical and Computer Engineering, Faculty of Engineering, International Islamic University Malaysia,
} Kuala Lumpur, Malaysia

\begin{tabular}{l} 
Article Info \\
\hline Article history: \\
Received Apr 26, 2020 \\
Revised Jun 4, 2021 \\
Accepted Jun 13, 2021 \\
\hline
\end{tabular}

\section{Keywords:}

Fuzzy logic

Intelligent read-out circuit

Radiation detector

Radiation level

Space radiation

\begin{abstract}
In the design of the satellite system, space radiation is among the important factors that need to be taken care of as it may contribute to system failure. This research aims to design and implement an intelligent read-out circuit to detect the level of radiation. It has the capability to measure the level of radiation. The capability of the designed device to measure the level of radiation and also the type of radiation exposure are the key components to be considered in the design of the system. In this research, the intelligent read-out circuit has been successfully designed and tested to detect the level of radiation. The results show the capability of the system to measure the level of radiation and determine the status of radiation level using both visual and sound indicators. The designed system is able to determine the level of radiation in a short time and strengthen by the danger-alert mechanism present in the system.
\end{abstract}

This is an open access article under the CC BY-SA license.

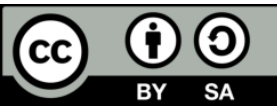

\section{Corresponding Author:}

Siti Fauziah Toha

Department of Mechatronics Engineering

Faculty of Engineering

International Islamic University Malaysia, Kuala Lumpur, Malaysia

Email: tsfauziah@iium.edu.my

\section{INTRODUCTION}

RazakSAT was Malaysia's second satellite and first remote sensing satellite launched into near equatorial orbit (NEqo) [1], [2]. RazakSAT carried a high-resolution camera that enabled it to take images for different types of applications [3]. Its orbiting path helped it to obtain an image that was six times better and cover almost $70 \%$ of the oceans, where whether phenomena such as La Nina originated [4]. Several countries in Asia, Latin America and the African continent showed their interest in utilizing the image captured by RazakSAT during that period. Unfortunately, a year after it has been launched on July 14, 2009, it fully malfunctioned on August 30, 2010 [5].

Other than factors of competency and transparency, the failure was suspected because of the space radiation due to the single-event upsets (SEU) categorized under single-event effects phenomena [6]. Space radiation is not equal to the kinds of radiation we experience here on Earth [7], [8]. Space radiation is made up of three kinds of radiation; trapped particles in the Earth's magnetic field, particles shot into space during solar flares (solar energetic particles); and galactic cosmic rays, which are the dominant source of radiation from outside our solar system [9], [10]. All of these kinds of space radiation are categorized under ionizing radiation. It is important to measure the level of radiation as a means for the user to be alerted to the radiation's level.

Space radiation which consists of electromagnetic radiation and charged particles accelerated to high velocities can cause irreparable damage to the human body in long-duration humans space missions [11]-[13]. This radiation consists of atoms in which electrons have been stripped away as the atom accelerated 
approaching the speed of light in interstellar space-finally, only the nucleus of the atom remains [14]. Single-event effects are the phenomena that happened because space radiation affects the digital device in many areas [15], [16]. A single iron will interact with the electronics chip; such as computer memories and microprocessors and caused changes or bit flip of the state of memory or register bits [17]. This even will create two types of results: non-destructive and destructive effects.

For the non-destructive effect, the information stored in the memory would be corrupted. This type of effect can be corrected or refreshed if the SEU is successfully detected [18]. Whereas for the destructive effect, it will destruct the microprocessor program and make the execution of the wrong command of the program. These effects are stochastic, as they happened because of the hit of single high energetic particles with specific circuit nodes [19]. In the case of a satellite, it changes the state of memory that makes the satellite cannot remember how it should work [8], [20].

Most semiconductor components have a high probability of radiation damage [21], [22]. Two things must be concerned to face this effect which is related to the reliability and performance of the components. This effect is particularly important to the detector to look into as their role to measure the radiations or particles that can cause damage to the components and exposure to the high radiation flux [23], [24]. Thus, it is very important to understand the effects of each type of radiation and properly design the device to reduce the impact of radiation on it. Hence, this research aims to design and implement an intelligent read-out circuit to detect the level of radiation. The capability of the designed device to measure the level of radiation and also the type of radiation exposure are the key components to be considered in the design of the system.

\section{RESEARCH METHOD}

The designed intelligent read-out circuit will specify the particular type of radiation and can measure proton, neutron, electron and heavy iron. The overview of the read-out circuit is shown in Figure 1. In this designed circuit, the Arduino Uno is chosen as the data acquisition (DAQ) for data collection from the sensors. The data from the sensors are then is fed into the computer for analysis. More details of the sensors used are described in the following subsection.

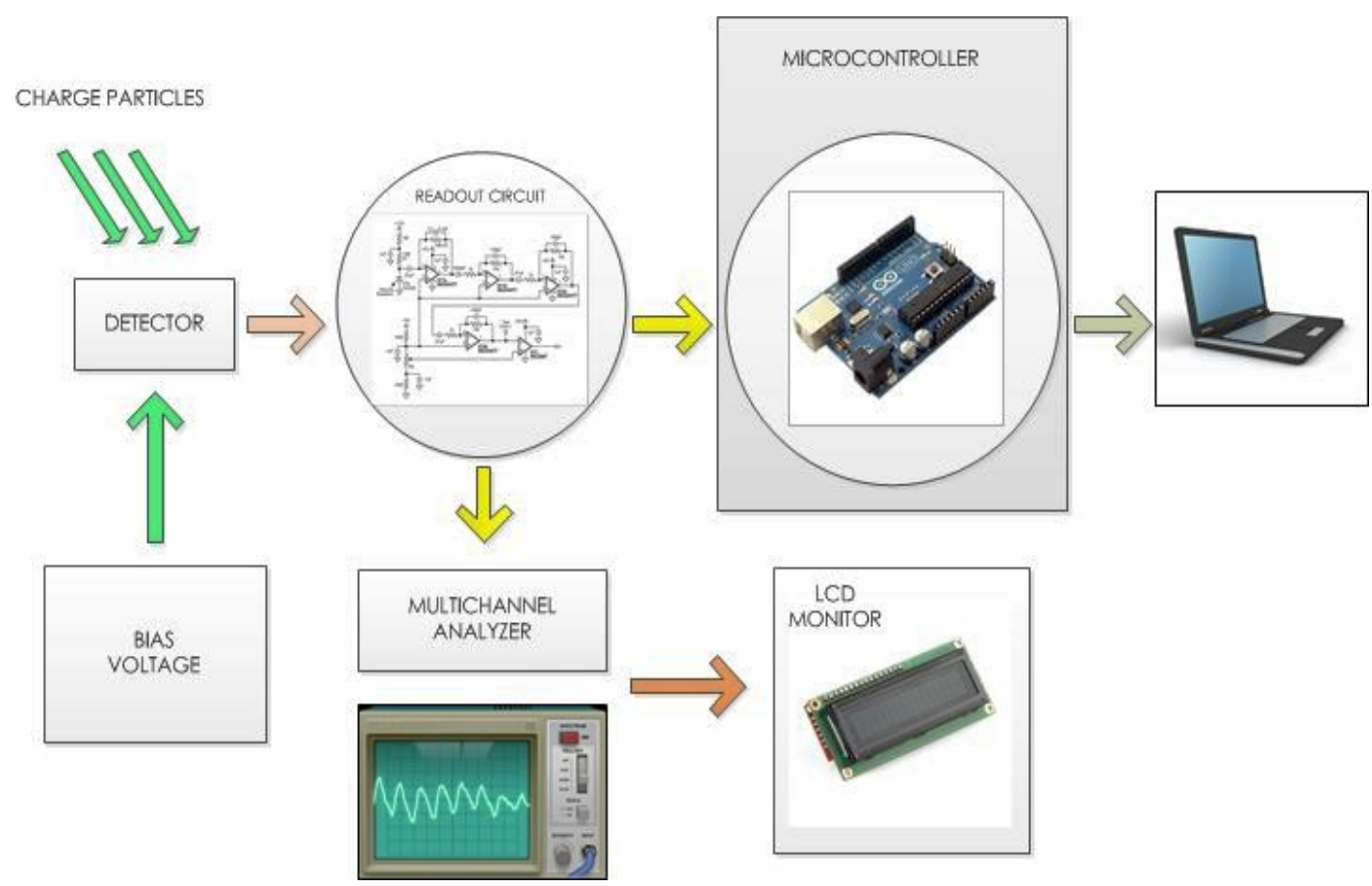

Figure 1. Overview of the intelligent read-out circuit

\subsection{Detector}

In this research, two suitable detectors can be used which are postal index number (PIN) photodiode and Geiger tube detector. These two detectors have the ability to determine the charged particles. A photodiode 
is a p-n junction or PIN structure. In this case, the PIN structure is selected because it faster in response. And the Geiger Muller tube sensor is used to detect the radiations.

\subsubsection{PIN photodiode}

It converts charge particles or light into current and this current can be converted into voltage. The current value produced is proportional to the characteristics of the incident radiation. A photodiode is a p-n junction or PIN structure. In this case, the PIN structure is selected because it faster in response. When the diode is strike by a photon of sufficient energy, it creates an electron and hole pair. This event is also known as the inner photoelectric effect. A built-in electric field of the depletion region plays an important role to make sure these carriers are swept from the junction if the absorption occurs in the junction's depletion region. When the electrons move toward the cathode and the holes toward the anode, a photocurrent is produced. The total current through the photodiode is the sum of the photocurrent and the dark current (current that flows with or without light), so the dark current must be minimized to get the maximum sensitivity of the device.

\subsubsection{Geiger muller tube}

The sensor used to detect the radiations is Geiger Muller tube. It consists of a tube with a low-pressure inert gas such as neon, helium, and halogen. There are electrodes inside the tube, between them are a potential difference of hundred volts, around $500 \mathrm{~V}$ but no current flowing inside it. The anode is located in the centre of the tube. Where as cathode is formed by the walls of the tube which is made entirely of metal or their inside surface coated with a conductor.

Some of the gas molecules will be ionized when the radiation; ionizing radiation enters through the tube. This will create electrons and positively charged ions. The electrons will go towards the anode and the ions to the cathode when the tube's electrodes accelerate them by using the electric field created. Further gas molecules will be ionized through collisions by the ion pairs which gain sufficient energy. Then creating an avalanche of charged particles. In short, an intense pulse of current is counted or measured and passes from the negative to the positive electrode.

\subsection{Radiation board tester}

In order to test radiation sensor board, vaseline glass beads are used. They contain small amount of uranium $(0.2 \%)$ which are classified as beta and gamma particles. Some gamma particles basically come from background radiation such as cosmic rays (sun and stars) and mineral in the Earth. Hence, by turning Geiger tube sensor, they can be detected easily. Their values depend on factors such as the altitude, the location and the efficiency of the Geiger tube. Their range are about 15-60 counts per minute. Hence, the total value detected by the sensor must be subtracted with the background radiation's value to get the exact value of radiation.

\subsection{Microcontroller}

In this research, the Arduino Uno is chosen to calculate the radiation level and consequently determine the type of radiation. It also has the capability to tell the users what the status is for each level of radiation. The control logic is designed based on the inputs and outputs from the sensors connected to the Arduino. For the designing phase, the Arduino is connected by the universal serial bus (USB) port to the computer for data processing and presentation. Once the control design phase is completed, the control logic is built and embedded in the Arduino to eliminate the need for a computer and enable a stand-alone system for the designed intelligent read-out circuit for space radiation detection.

\section{RESULTS AND DISCUSSION}

In this section, the designed intelligent read-out circuit is tested and analysed. The complete system of the device is shown in Figure 2 (a) and Figure 2 (b) which comprises the read-out circuit of the device and the prototype of the system. The system is designed to alert the user about the presence of radiation in terms of its level and type. The fuzzy logic controller is applied in the system to classify the value, the type and the effect of radiation. The application of the fuzzy logic is due to the ability of this technique to the ability of fuzzy logic in dealing with the nonlinearities and uncertainties of the system [25]-[27]. The inputs and output of the control logic designed for the intelligent read-out circuit are shown in Figure 3. And the membership functions of the system are illustrated in Figure 4. 


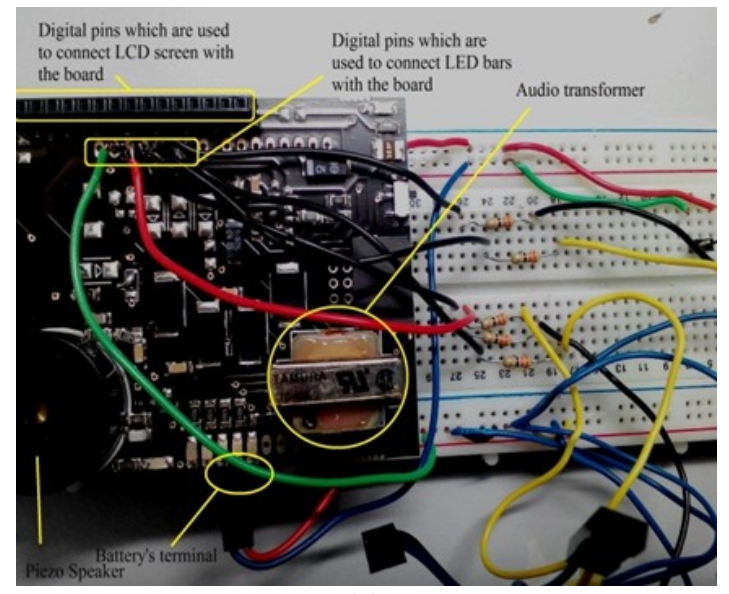

(a)

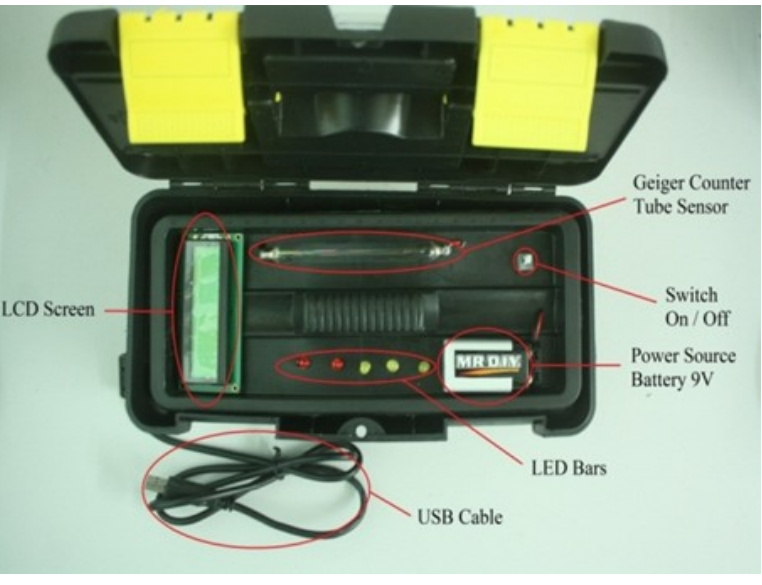

(b)

Figure 2. Complete system: (a) read-out circuit and (b) prototype of the system

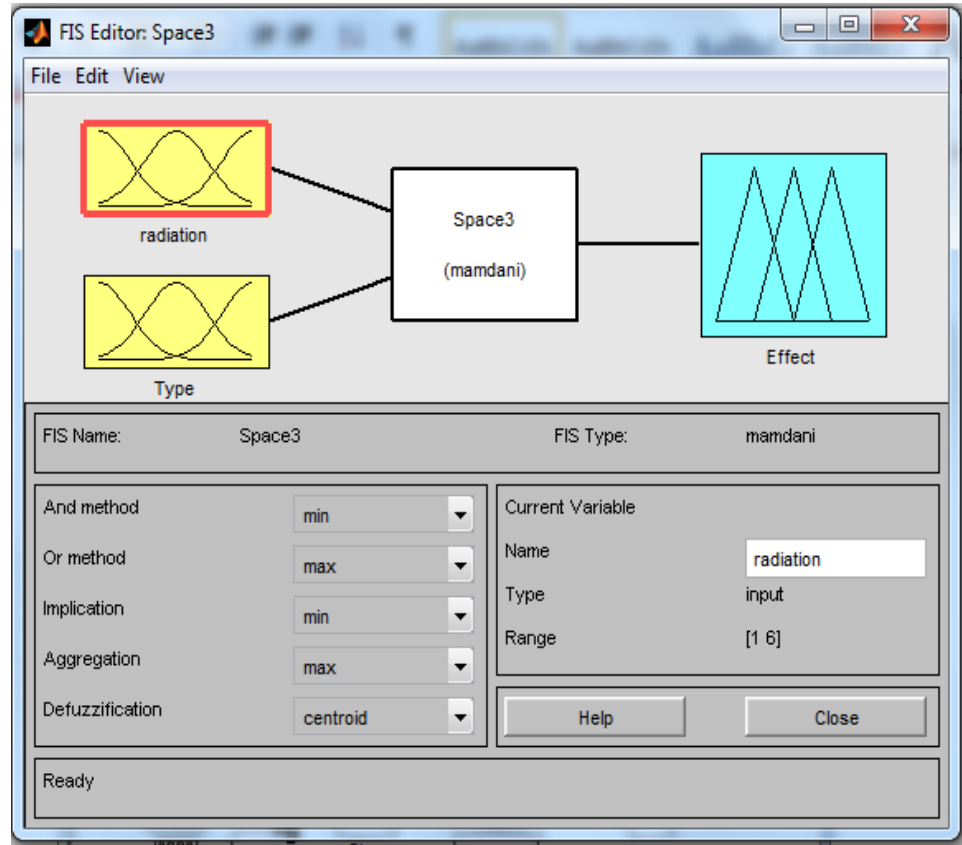

Figure 3. Inputs (value and type) and output (effect) of the fuzzy logic

The level of radiation is translated into two forms to ease the user: the value of the radiation level and the status of radiation. In terms of radiation level detection, the system is configured to determine the level of radiation in five stages namely safe, moderate, warning, danger and damaged. The system must be able to determine the level of radiation as fast as possible. The radiation level is measured in terms of count per minute (CPM). The board counts pulses for 10 seconds. To get in terms of minutes, multiply the pulses by 6 . Most dosimeters use micro-Sieverts per hour $(\mu \mathrm{SV} / \mathrm{h})$ as a standard value for radiation dose. In order to get the radiation or energy value of $\mu \mathrm{SV} / \mathrm{h}$, the conversion is made by multiplying CPM by 0.00812 as describes in (1). The conversion factor depends on the Geiger tube itself; the shape, the size, the type of particle measured, the material and others. Normally this factor is made by the manufacturer during the calibration process. Based on Figure 5, it can be observed that within four seconds, the radiation value increased from the safe condition with CPM rated around 0 to the damaged conditions with CPM value around 100 .

$C P M \times 0.0812=\mu S V / h$ 


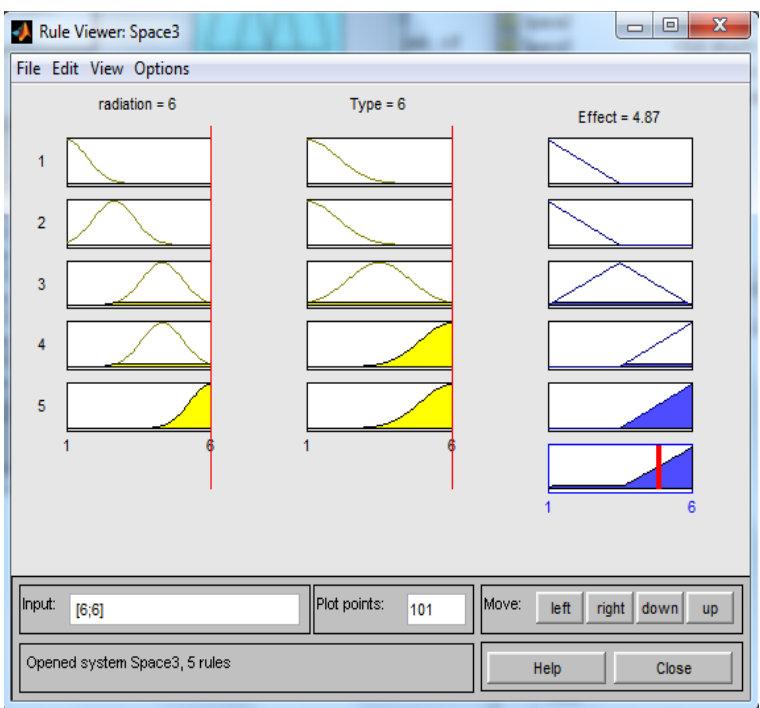

(a)

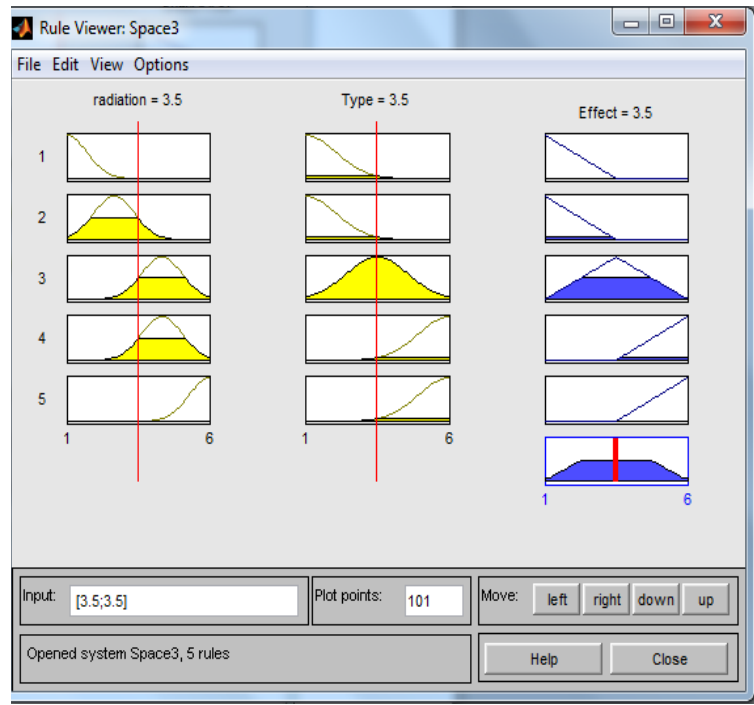

(b)

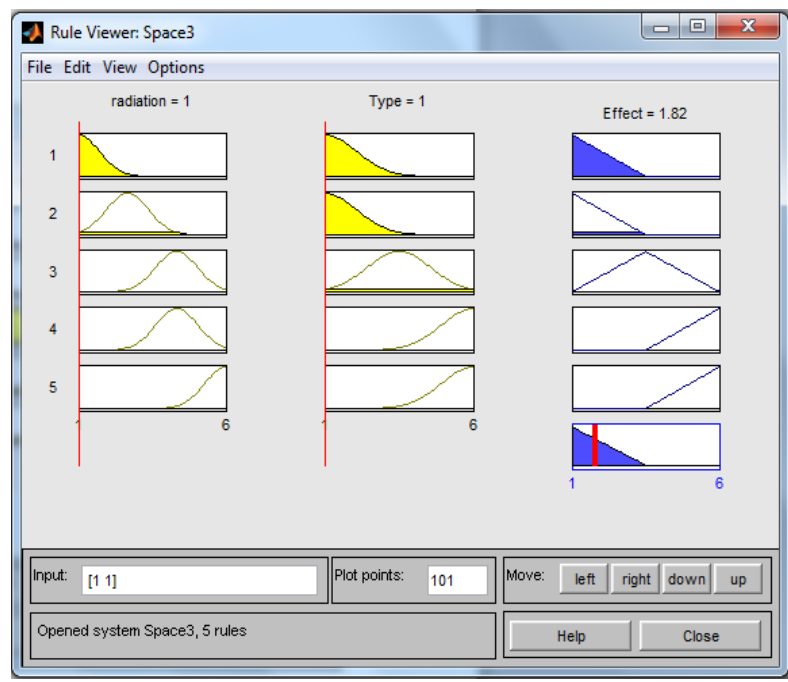

(c)

Figure 4. Membership function; (a) radiation damage, (b) interference, (c) single event upset

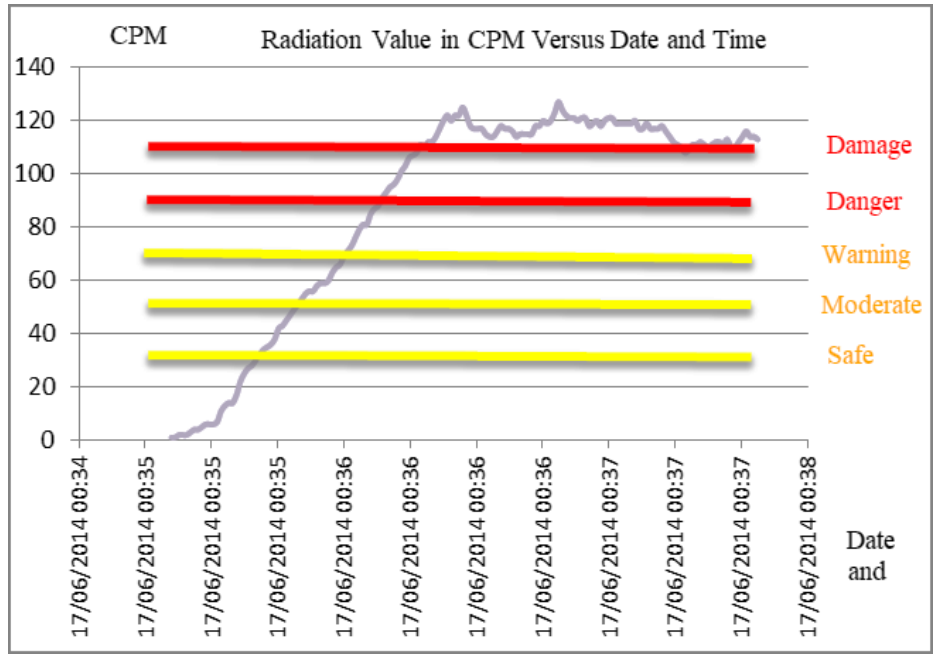

Figure 5. Graph of radiation value in CPM versus date and time 
Another feature of the intelligent read-out circuit is the indication of the radiation status on the device. This feature enables the user to know the level of radiation by just looking at the liquid crystal display (LCD) screen, light-emitting diode (LED)s and Piezo speakers in real-time. Table 1 shows the summary of LCD and LED indicators reflecting the status of the radiation. LED bars will turn on based on the status of the radiation. Figure 6(a-f) illustrates how the real system works from the safe level radiation in Figure 6 (a) to the damage radiation level in Figure 6 (f). The red LED are representing both danger and damage level to imply the destructive potential hazards present at those stages. Also, the piezo speaker produces the sound "chirp" each time a pulse is generated. It is connected to the output of the Geiger tube directly. The higher the value of radiation, the more frequent the chirping sound. This piezo speaker is bound on the radiation board.

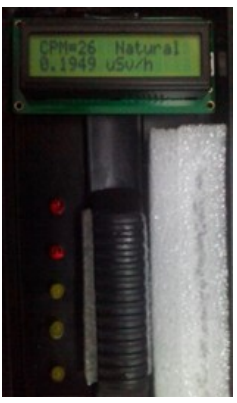

(a)

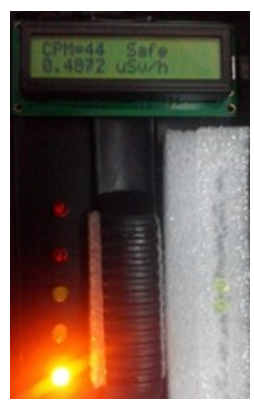

(b)

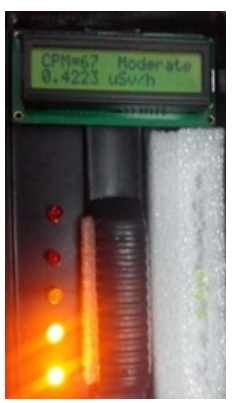

(c)

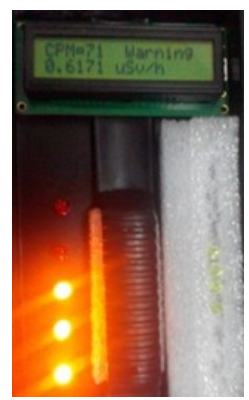

(d)

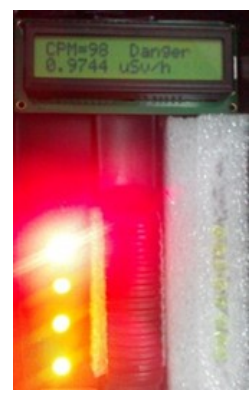

(e)

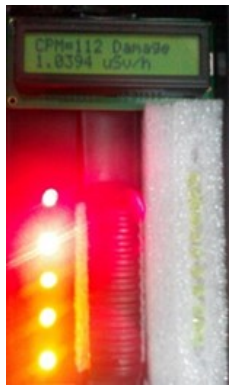

(f)

Figure 6. LCD screen and LED bars indicator: (a) natural status, (b) safe status, (c) moderate status, (d) warning status, (e) danger status, (f) damage status

\begin{tabular}{lll} 
Table 1. Radiation value, & status and LED bars' indicator \\
\hline Radiation Value $((\mu \mathrm{SV} / \mathrm{h})$ & Status & \multicolumn{1}{c}{ LED bars } \\
\hline $0-30$ & Natural & - \\
$31-60$ & Safe & Yellow 1 ON \\
$61-70$ & Moderate & Yellow 2 ON \\
$70-90$ & Warning & Yellow 3 ON \\
$91-110$ & Danger & RED 1 ON \\
111 and above & Damage & RED 2 ON \\
\hline
\end{tabular}

\section{CONCLUSION}

This research aims to design and implement an intelligent read-out circuit to detect the level of radiation. The intelligent read-out circuit has been successfully designed and tested to detect the level of radiation. It has the capability to measure the level of radiation and determine the status of radiation level with the LCD and LED serve as a visual indicator and piezo speaker act as a sound indicator. The designed system is able to determine the level of radiation in a short time and strengthen by the danger-alert mechanism present in the system. For future study, some improvement can be made focusing on how to make comprehensive protection to the system from the effect of radiation.

\section{ACKNOWLEDGEMENTS}

The authors would like to express their gratitude to International Islamic University Malaysia (IIUM) for providing facilities to conduct this research and acknowledge financial assistance from the Ministry of Higher Education Malaysia under the Fundamental Research Grant Scheme, by grant No. FRGS19-053-0661.

\section{REFERENCES}

[1] A. Ahmad, "Classification simulation of RazakSAT satellite," Procedia Engineering, vol. 53, pp. 472-482, 2013, doi: 10.1016/j.proeng.2013.02.061.

[2] M. Z. Hasan, S. Yaacob, A. Ahmed, S. B.Yaakob, M. H. Idris, and M. A. M. Said, "Analysis the condition of RazakSAT based on attitude sensor of atttitude determination system data," Applied Mechanics and Materials, vol. 785, pp. 739-743, 2015, doi: 10.4028/www.scientific.net/AMM.785.739. 
[3] N. S. Wai, A. A. Tan, J. W. S. Mee, M. Ismail, and M. D. Subari, "Preflight radiometric calibration of RazakSAT ${ }^{\text {TM, " }}$ 2009 4th International Conference on Recent Advances in Space Technologies, 2009, pp. 277-282, doi: 10.1109/RAST.2009.5158212.

[4] M. Hashim, et al., "Geometric and radiometric evaluation of Razaksat medium-sized aperture camera data," International journal of remote sensing, vol. 34, no. 11, pp. 3947-3967, 2013, doi: 10.1080/01431161.2013.770581.

[5] C. Pohl and M. Hashim, "Increasing the potential of Razaksat images for map-updating in the Tropics," in IOP Conference Series: Earth and Environmental Science, 2014, vol. 18, no. 1, pp. 1-6, doi: 10.1088/1755$1315 / 18 / 1 / 012029$.

[6] W. Suparta and S. K. Zulkeple, "Investigating space radiation environment effects on communication of Razaksat1," Journal of Aerospace Technology and Management, vol. 10, pp. 1-12, 2018, DOI: 10.5028/jatm.v10.815.

[7] V. U. J. Nwankwo, N. N. Jibiri, and M. T. Kio, The impact of space radiation environment on satellites operation in near-Earth space, intechopen.com. [Online]. Available: https:/www.intechopen.com/online-first/the-impact-ofspace-radiation-environment-on-satellites-operation-in-near-earth-space. (Accessed: Dec. 13, 2020)

[8] C. Schuy, et al., "Experimental assessment of lithium hydride's space radiation shielding performance and monte carlo benchmarking," Radiation Research, vol. 191, no. 2, pp. 154-161, 2019, doi: 10.1667/RR15123.1.

[9] Y. Yan, K. Zhang, G. Zhou, and W. Hu, "MicroRNAs responding to space radiation," International Journal of Molecular Sciences, vol. 21, no. 18, p. 6603, 2020, doi:10.3390/ijms21186603.

[10] M. Moreno-Villanuev and $\mathrm{H}$. Wu, "Radiation and microgravity - Associated stress factors and carcinogensis," REACH, vol. 13, p. 100027, 2019, doi: 10.1016/j.reach.2019.100027.

[11] J. Barthel and N. Sarigul-Klijn, "Importance of spherical shell models for radiation shielding designs on space missions," Journal of Spacecraft and Rockets, vol. 56, no. 5, pp. 1658-1661, 2019, doi: 10.2514/1.A34410.

[12] J. DeWitt and E. R. Benton, "Shielding effectiveness: A weighted figure of merit for space radiation shielding," Applied Radiation and Isotopes, vol. 161, p. 109141, 2020, doi: 10.1016/j.apradiso.2020.109141.

[13] F. Yatagai, M. Honma, N. Dohmae, and N. Ishioka, "Biological effects of space environmental factors: A possible interaction between space radiation and microgravity," Life Sciences in Space Research, vol. 20, pp. 113-123, 2019, doi: 10.1016/j.1ssr.2018.10.004.

[14] N. Ya'acob, A. Zainudin, R. Magdugal, and N. F. Naim, "Mitigation of space radiation effects on satellites at Low Earth Orbit (LEO)," 2016 6th IEEE International Conference on Control System, Computing and Engineering (ICCSCE), 2016, pp. 56-61, doi: 10.1109/ICCSCE.2016.7893545.

[15] R. A. Weller, et al., "Monte Carlo Simulation of Single Event Effects," in IEEE Transactions on Nuclear Science, vol. 57, no. 4, pp. 1726-1746, Aug. 2010, doi: 10.1109/TNS.2010.2044807.

[16] E. A. Yahya, R. Kannan, and L. Lee, "Simulation study of single event effects sensitivity on commercial power MOSFET with single heavy ion radiation," Bulletin of Electrical Engineering and Informatics, vol. 8, no. 4, pp. 12601267, 2019, doi: 10.11591/eei.v8i4.1611.

[17] S. J. H. Pirzada, A. Murtaza, L. Jianwei, and T. Xu, "Single Event Effects Tolerant AES-CTR Implementation for Authentication of Satellite Communication," International Journal of Computer and Communication Engineering, vol. 8, no. 4, pp. 178-183, 2019, doi: 10.17706/IJCCE.2019.8.4.178-183.

[18] A. S. Gohardani, "Enabling revolutionary power components for future space missions: Progress in metal-oxidesemiconductor field-effect transistors," in AIAA Scitech 2019 Forum, 2019, pp. 1-10, doi: 10.2514/6.2019-1519.

[19] K. Yarita et al., "Proton Radiation Damage Experiment for X-Ray SOI Pixel Detectors," Nuclear Instruments and Methods in Physics Research Section A: Accelerators, Spectrometers, Detectors and Associated Equipment, vol. 924, pp. 457-461, 2019, doi: 10.1016/j.nima.2018.09.057.

[20] J. Bi, "Radiation effects of floating-gate (FG) and charge-trapping (CT) Flash memory technologies," 2019 International Conference on IC Design and Technology (ICICDT), 2019, pp. 1-3, doi: 10.1109/ICICDT.2019.8790893.

[21] M. Ibarra, et al., "EDRA, the Argentine facility to simulate radiation damage in space," Radiation Physics and Chemistry, vol. 154, pp. 79-84, 2019, doi: 10.1016/j.radphyschem.2018.08.032.

[22] J. Kim, et al., "Radiation damage effects in Ga2O3 materials and devices," Journal of Materials Chemistry C, vol. 7, no. 1. pp. 10-24, 2019, doi: 10.1039/C8TC04193H.

[23] K. D. Bartlett, D. D. S. Coupland, D. T. Beckman, and K. E. Mesick, "Proton irradiation damage and annealing effects in ON Semiconductor J-series silicon photomultipliers," Nuclear Instruments and Methods in Physics Research, Section A: Accelerators, Spectrometers, Detectors and Associated Equipment, vol. 969, p. 163957, 2020, doi: 10.1016/j.nima.2020.163957.

[24] A. Coburger, J. Likar, and C. Smith, "Bayesian Radiation Modeling for Spacecraft Reliability Prediction," 2019 IEEE Aerospace Conference, 2019, pp. 1-9, doi: 10.1109/AERO.2019.8741783.

[25] E. C. Abana, M. J. Palatan, C. P. Pascual, C. M. Mateos, and S. A. Galasinao, "Fuzzy logic based fan controller of indoor air purifier fan," Indonesian Journal of Electrical Engineering and Computer Science, vol. 17, no. 3, pp. 12661274, 2020, doi: 10.11591/ijeecs.v17.i3.pp1266-1274.

[26] M. Subramani and V. B. Kumaravelu, "A fuzzy based vertical handover network selection scheme," Indonesian Journal of Electrical Engineering and Computer Science, vol. 17, no. 1, pp. 324-330, 2020, doi: 10.11591/ijeecs.v17.i1.pp324-330.

[27] K. W. Nasser, S. J. Yaqoob, and Z. A. Hassoun, "Improved dynamic performance of photovoltaic panel using fuzzy logic-MPPT algorithm," Indonesian Journal of Electrical Engineering and Computer Science, vol. 21, no. 2, pp. 617 624, 2021, doi: 10.11591/ijeecs.v21.i2.pp617-624. 


\section{BIOGRAPHIES OF AUTHORS}
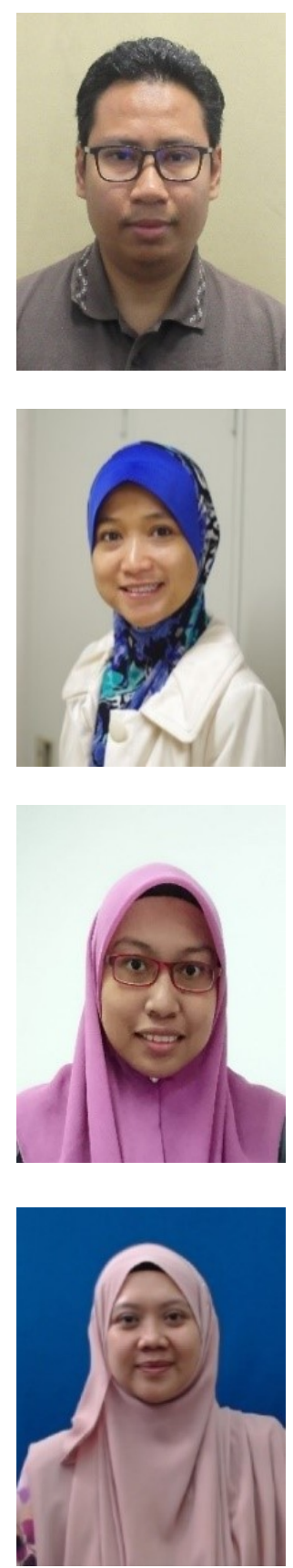

'Umar Abd Aziz is currently working at Nexperia Malaysia Sdn Bhd as Senior Test Product Engineer. He received B. Eng (Hons) in Mechatronics Engineering from International Islamic University Malaysia (IIUM). Has seven years working experience in semiconductor industry as Product Engineer; Test Program development, Bench and data analysis.

Siti Fauziah Toha is currently an Associate Professor at the Department of Mechatronics Engineering, International Islamic University Malaysia (IIUM). She received B. Eng (Hons) in Electrical and Electronics Engineering from University Technology Petronas and later received MSc from Universiti Sains Malaysia in electrical engineering. She was then completed her PhD in Automatic Control and Systems Engineering from The University of Sheffield in 2010. Dr Toha is a senior member of IEEE and also a Professional Engineer in Malaysia as well as a Chartered Engineer with Engineering Council, The Institution of Engineering and Technology, United Kingdom. She is also an active member of Young Scientist Network, Academy of Sciences Malaysia (YSN-ASM).

Rabiatuladawiah Abu Hanifah was born in Kuala Lumpur, Malaysia. She received the B. Eng (Hons) in Mechatronics Engineering and MSc degrees in Mechatronics Engineering from International Islamic University Malaysia in 2011 and 2014 respectively. In 2020, she successfully graduated and completed her PhD from the same university researching on the enhancement of complex controller optimization for the electric vehicle. Her research interests are in system controller parameter and performance optimization using various computational intelligence methods.Dr. Rabiatul is a student member of IEEE and also a registered graduate engineer of Board of Engineers Malaysia. In ITEES, IEEE Transactions journals and other scientific publications, she has served as invited reviewer.

Nurul Fadzlin Hasbullah is currently an Associate Professor at the Department of Electrical and Computer Engineering, Faculty of Engineering. She graduated with a First Class Honours from Cardiff University, Wales, with a Bachelor of Engineering in 2001. Later, she worked as an Integrated Chip Design Engineer in Malaysia Microelectronics Solution, Cyberjaya for a year before joining academia, teaching at the University Tenaga Nasional (Bangi, Malaysia) as a tutor. In 2003, she moved to International Islamic University Malaysia as an Assistant Lecturer. She obtained her PhD from the University of Sheffield, UK in 2010 researching on the electrical and optical characteristics of quantum dot laser structures. Her research interests continue in the areas of semiconductor device characterization, optical detectors and radiation hard devices. 